\title{
Valoración del F. S. H. por la Citología
}

\author{
Profesor Pedro Nel Cardona C. \\ Doctor Fernando Cardona A. \\ Doctor Ramiro Zúñiga.
}

\section{INTRODUCCION}

En pacientes con ovarios normales, la admin:stración de gonadotropinas séricas produce un aumento del porcentaje eosinófilo en las células exfoliadas vaginales (1). En las pacientes con ovarios menopánicos y en aquellas cuyo desarrollo ovarico es rudimentario no se aprecia la respuesta eosinófila al estímulo gonadotropínico sérico exógeno (2). El estudio clínico de esta prueba nos permite valorar si el F. S. H. está aumentado o disminuido.

\section{Material y Métodos}

Se estudiaron 8 pacientes, en 6 el control fué por colpocitología y en las otras 2 por medio del urocitograma. Los extendidos se colo rearon con la técnica de Papamiltiades-Shorr. Se tomaron muestras previas para establecer el índice cosinófilo de cada paciente y luego se inyectaron $1.000 \mathrm{U}$. de gonadotropinas séricas diarias por vía intramuscular durante 3 dias y se continuó con los extendidos citológicos hasta obtener el nivel inicial de eosinofilia.

\section{Resultados y Comentarios}

En dos pacientes con Sindrome de Shehan se encontró una discreta respuesta eosinófila, lo que nos prueba la capacidad funcional de los ovarios y nos demuestra que la hipofunción gonadal es debida a una disminución de las gonadotrofinas hipofisiarias. Figuras Nos. 1 y 2. 


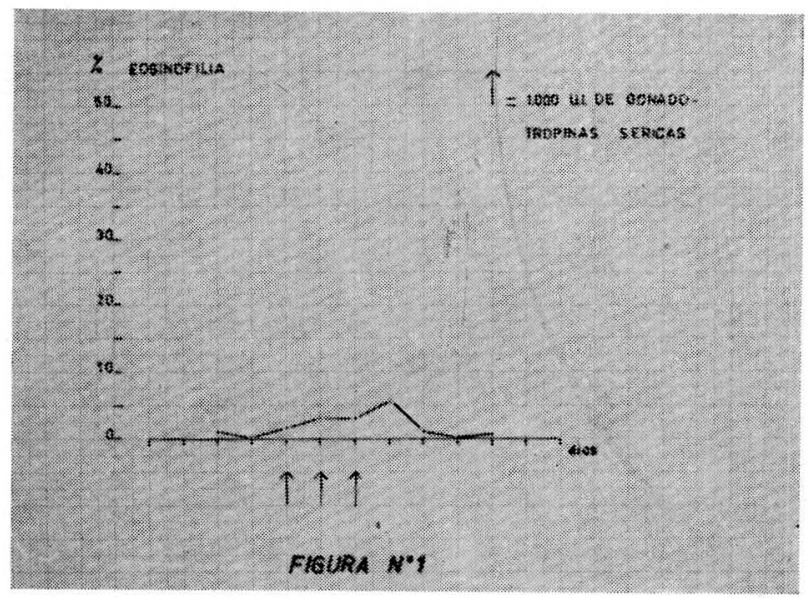

FIGURA N: 1

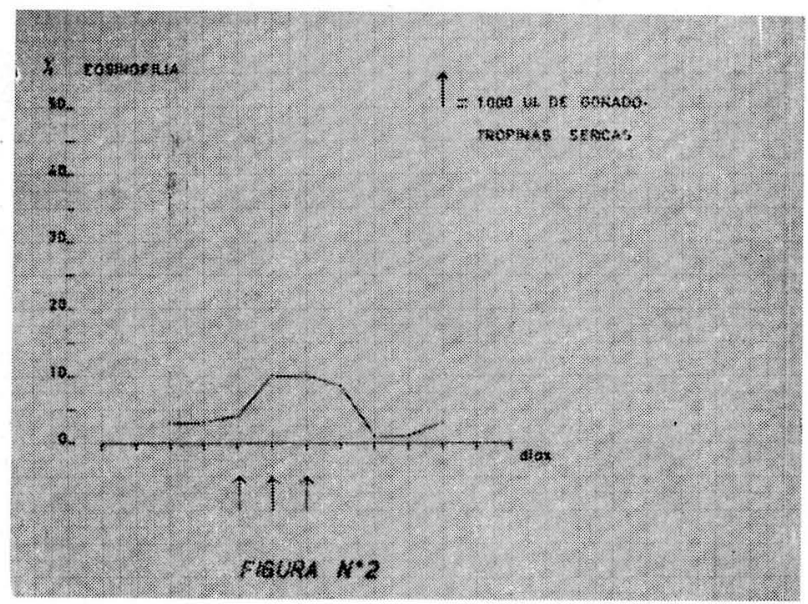

FIGURA No 2

En una paciente con amenorrea primaria no se encontró respuesta eosinófila, lo que nos indicó la falta de ovarios funcionantes y por consiguiente el exceso de gonadotropinas; a esta paciente posteriormente se la practicó una laparotomía exploradora y se encontraron unos ovarios muy rudimentarios. Figura № 3. 


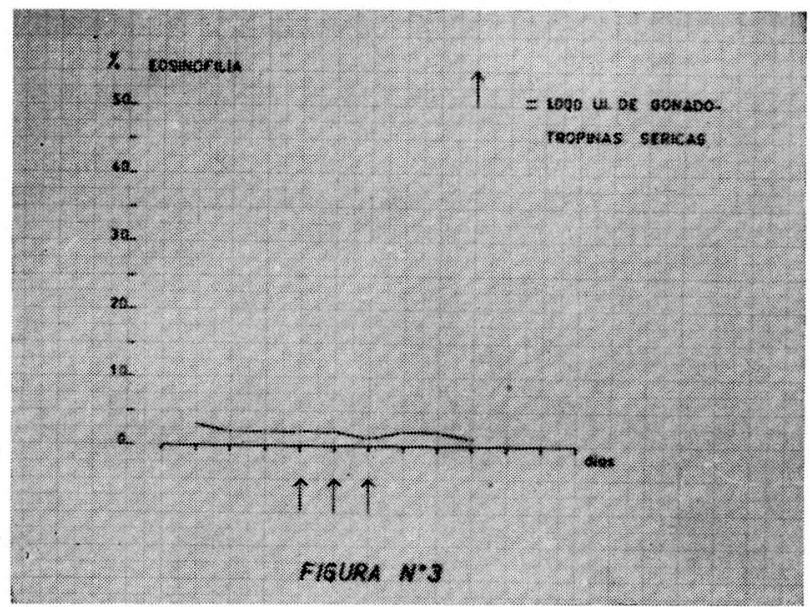

FIGURA No 3

En dos pacientes con amenorrea primaria se encontró una muy leve respuesta eosinófila, lo cual nos indicó la presencia de ovarios rudimentarios pero con capacidad de responder a las gonadotrofinas, lo que nos indicó que las gcnadotrofinas están normales o discretamente aumentadas. Figuras Nos. 4 y 5.

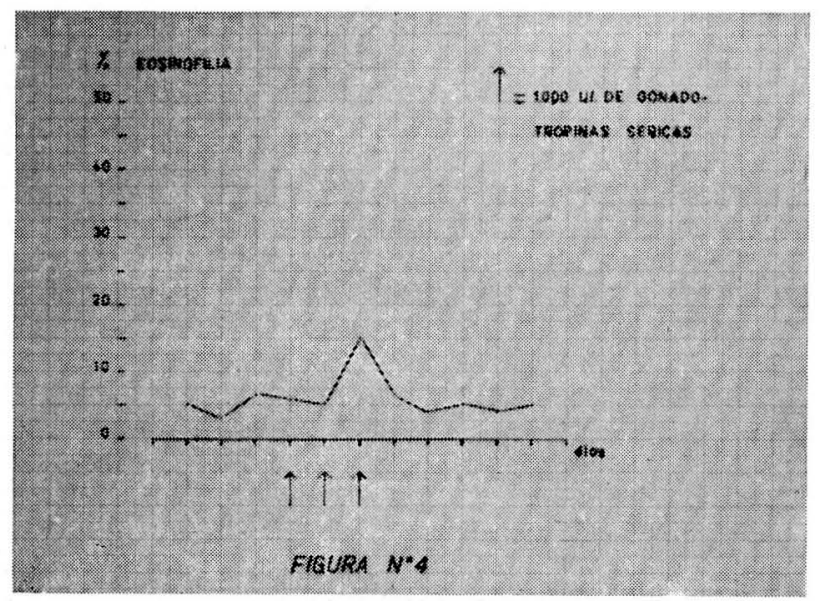

FIGURA N: 4 


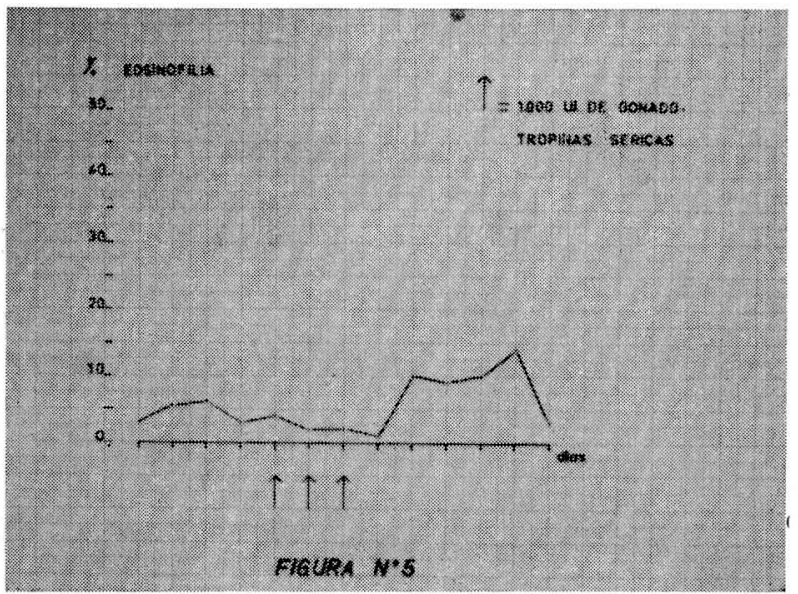

FIGURA $\mathbf{N}: 5$

En una paciente post-menopáusica no encontramos respuesta eosinófila lo que nos probó la incapacidad funcional de sus ovarios y nos explicó sus extendidos atróficos. En esta paciente su última menstruación se había presentado hacía 15 años y por lo tanto las gonadotrofinas ya no estaban aumentadas. Figura No 6 .

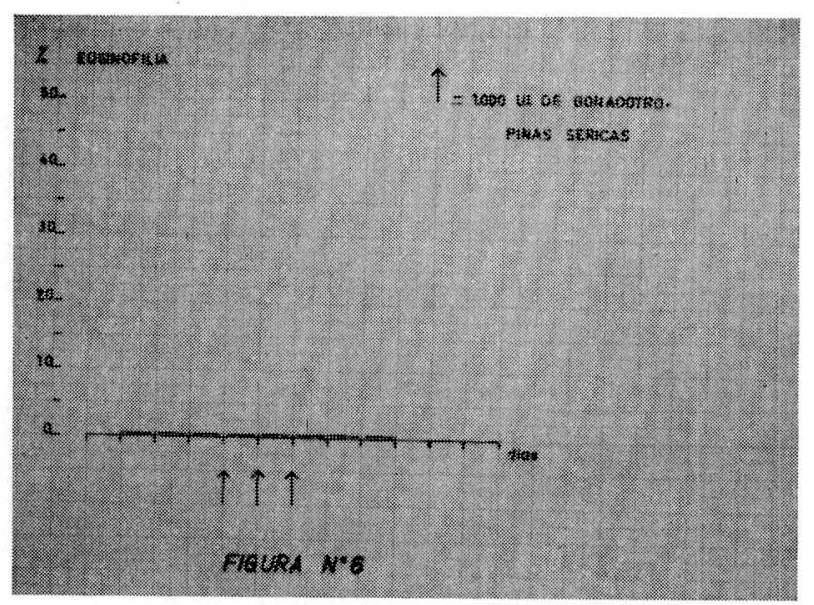

FIGURA N: 6 
En una paciente con amenorrea primaria se encontró una muy franca respuesta eosinófila lo que nos indicó que sus ovarios eran normales y que la causa de su amenorrea residia en una hipofunción gonadotrófica hipofisiaria. Figura No 7.

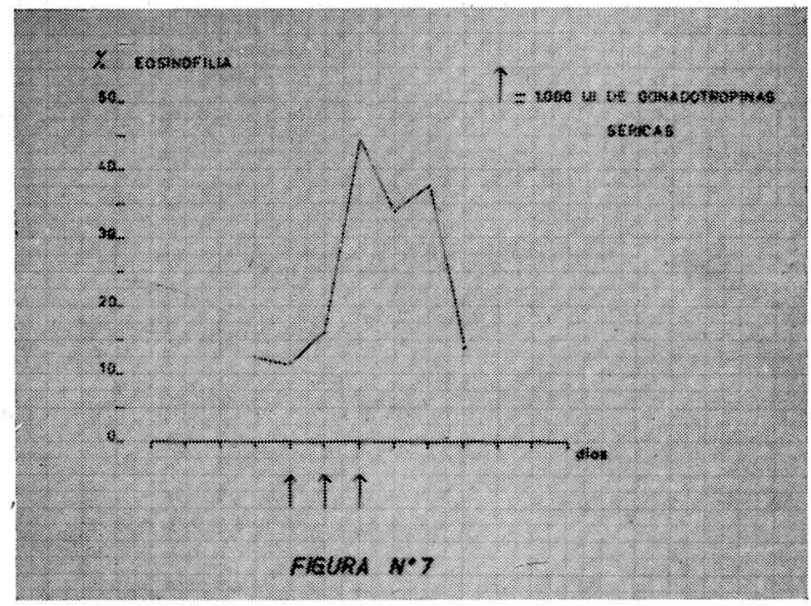

FIGURA $N$ ํ. 7

En una enferma con amenorrea después de un tratamiento con Radium intrauterino, para una hiperplasia persistente, se encontró una marcada respuesta eosinófila a las inyecciones de Gonadotrofinas séricas, lo que indicó que sus ovarios no sufrieron con el tratamiento actínico, que sus gonadotrofinas eran normales y que hipofisis y ovarios permitian un injerto de endometrio. Figura № 8 .

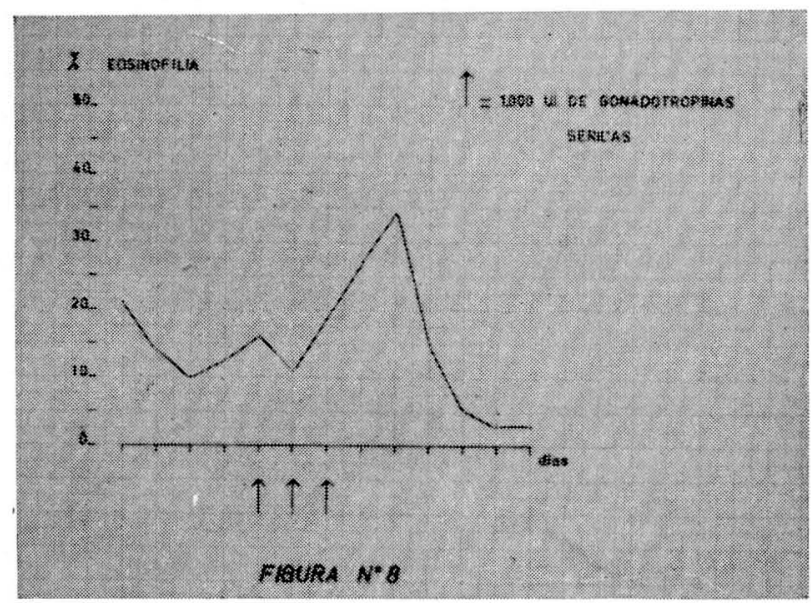

FIGURA N: 8 


\section{CONCLUSIONES}

La respuesta colpocitológica a las gonadotrofinas séricas es de utilidad clinica para valorar el funcionamiento hipofisiario y ovarico; esta prueba tiene el gran valor de que permite confirmar tanto las gonadotrofinas hipofisiarias altas como las bajas, hechos que no podemos objetivar por las disificaciones biológicas a ratas impúberes. pués este método solo nos indica cantidades normales o elevadas.

\section{BIBLIOGRAFIA}

1- J. PAUL PUNDEL. Les Frottis Vaginaux et Cervicaux. pag. 153 ed. Maszon 1950 París.

2-- J. PAUL PUNDEL. Acquisitions Recentes en Cytologie Vaginale Hormonale. pag. 211 ed. Masson. 1957 París. 